\title{
The Association between Perceived Stress, Psychological Distress, and Job Performance During the COVID-19 Pandemic: the Buffering Role of Health-Promoting Management Practices
}

\section{Sophie Meunier ${ }^{1}$. Laurence Bouchard ${ }^{1}$ (D) . Simon Coulombe ${ }^{2}$. Marina Doucerain ${ }^{1} \cdot$ Tyler Pacheco $^{3} \cdot$ Emilie Auger $^{2}$}

Accepted: 14 December 2021 / Published online: 26 January 2022

(c) Associação Brasileira de Psicologia 2022

\begin{abstract}
The first objective of the present study was to investigate the association between perceived stress, psychological distress, and job performance among workers during the first wave of the COVID-19 pandemic. As a second objective, this study sought to examine whether management practices aimed at promoting employees' psychological health can moderate this relationship. A total of 435 workers answered a self-reported questionnaire assessing perceived stress, psychological distress, and job performance as well as health-promoting management practices adopted by their manager, which focused on establishing work structure, demonstrating consideration and showing support. Results indicated that perceived stress was negatively associated with job performance and this relation was mediated by psychological distress. Moderation analysis revealed that for low and average levels of health-promoting management practices, perceived stress was negatively associated with job performance. However, when workers perceived that their supervisor adopted several health-promoting management practices, the association between perceived stress and job performance became non-significant. Also, the association between perceived stress and psychological distress was positive and significant for all levels of health-promoting management practices, but its strength diminished as management practice increased. Finally, a moderated mediation analysis indicated that the indirect effect of perceived stress on job performance through psychological distress was moderated by health-promoting management practices. This study contributes to the advancement of knowledge by demonstrating that, in a context of a crisis which can cause considerable stress, such as the COVID-19 pandemic, health-promoting management practices can buffer the deleterious effect of perceived stress on psychological health and job performance.
\end{abstract}

Keywords Management practices $\cdot$ COVID-19 $\cdot$ Psychological distress $\cdot$ Stress $\cdot$ Job performance

Extended author information available on the last page of the article 


\section{Introduction}

The crisis associated with the new coronavirus pandemic (COVID-19) continues to have significant repercussions around the world (Amirkhan, 2020; Brooks et al., 2020). The pandemic itself has generated numerous stressors among people, such as the fear of being infected, the threat it poses for loved ones, social isolation, and altered daily routines (World Health Organization, 2020). During the first lockdown in Canada (April and May 2020), 28\% of the country's population reported experiencing moderately or extremely stressful days (Statistics Canada, 2020a). When taking into account the spillover effect between home and work life (Crouter, 1984), it is probable that this stress not only affected everyone's personal life, but was also transferred to the workplace and added to the other stressors in that specific environment. Indeed, in order to respect government policies such as social distancing measures to prevent the spread of the coronavirus, Canadian workers have had to make drastic changes to their lives (Statistics Canada, 2020b). For example, 4.7 million workers became teleworkers at the beginning of the lockdown (Statistics Canada, 2020c). These changes have undoubtedly generated stress for workers, which may subsequently have increased their psychological distress and reduced their work performance (Gilboa et al., 2008; LePine et al., 2005; Lim \& Tai, 2014). It is thus important to identify different factors that may explain and buffer these associations, in the context of a crisis such as the COVID-19 pandemic. Health-promoting management practices (i.e., concrete behaviors adopted by manager in a daily basis) could be an important factor to consider. Indeed, specific daily managerial behaviors and practices appear to play an important role in preserving employees' psychological health (Biron et al., 2016; Kuoppala et al., 2008), possibly also improved their job performance, especially when facing this type of crisis. However, no study to date has examined these associations empirically. Thus, this study's first objective is to fill this gap by examining the association between workers' perceived stress, psychological distress, and job performance during the first wave of the COVID-19 pandemic (March and April 2020). This study also seeks to investigate, as a second objective, whether these relationships can be moderated by health-promoting management practices. In doing so, the present study intends to provide managers with insights about concrete actions that can be adopted to reduce the deleterious effects of the high level of stress caused by the COVID-19 pandemic on employees (e.g., psychological distress, decreased performance), as well as on their organization (e.g., productivity decline).

\section{Stress and Psychological Distress Among Workers in a Crisis Context}

Selye (1956) defined stress as a nonspecific response to any demanding situation. However, over the years, researchers have come to define stress with greater precision, indicating that stress is not caused by a demand per se, but by the individual's appraisal of that demand (Folkman \& Lazarus, 1990; Lazarus, 1966). According to Fink (2016), a demand interpreted as an uncontrollable, aversive challenge causes 
individuals to react, provoking stress and making them anxious. Given the unpredictable and uncontrollable nature of multi-dimensional worldwide impacts of the COVID-19 crisis, it has likely created a great level of stress for individuals. Indeed, a recent study conducted among Canadians in early 2020 found that $85.7 \%$ reported a moderate or high level of stress (Nwachukwu et al., 2020). Furthermore, it seems that workers have been particularly affected by this crisis. Indeed, aside from disruptions to their personal lives, the COVID-19 crisis has also generated a variety of work-related challenges such as job insecurity, absence of personal boundaries while teleworking with a spouse or children at home, or social isolation from colleagues and one's supervisor (Hamouche, 2020; Pacheco et al., 2020; Shockley et al., 2020).

Although it is recognized that stress has an adaptive value, as it allows individuals to find the energy necessary to take action, it can be harmful for mental health when it is chronic or overly intense. Indeed, psychological distress, which is characterized by symptoms related to anxiety and depression (Massé et al., 1998; Préville, 1995; Veit \& Ware, 1983), can result from continued stress with which it has been difficult to cope (Drapeau et al., 2011; Marchand, 2004). Thus, crises that generate a high and prolonged level of stress can be harmful to individuals' mental health. In this vein, studies conducted in the context of various crises have demonstrated the deleterious effects of stress on psychological health (Bao et al., 2020; Chan \& Huak, 2004; Nickell et al., 2004). For example, a study conducted by Nickell et al., (2004) during the 2002-2004 SARS crisis indicated that the stress induced by the epidemic was associated with psychological distress among workers. In sum, stress is highly likely to lead to psychological distress among workers in times of crisis.

\section{Stress, Psychological Distress, and Job Performance}

Job performance is defined as the behaviors of an employee that contribute directly, or indirectly, to the achievement of an organization's objectives (Borman \& Motowildo, 1993; Rich et al., 2010). Previous research has demonstrated that a high level of job stress and psychological distress can lead to low job performance (Jamal, 2007; Motowildo et al., 1986; Wright \& Cropanzano, 2000). In the context of the COVID-19 crisis, workers' stress may have significantly impacted their work performance (Sinclair et al., 2020). Indeed, according to the spillover effect, behaviors, moods, and emotions, such as stress, in one domain of life (i.e., personal life) are likely to affect another domain (i.e., work life) (Crouter, 1984; Ford et al., 2007; Mennino et al., 2005). In this vein, Lim and Tai (2014) indicate that interpersonal home stressors, such as family incivility, have been associated negatively with work performance. Also, according to Conservation of Resources Theory (COR; Hobfoll, 1989), individuals tend to gain resources in order to achieve a goal or respond to demanding situations. However, after an initial loss of resources in responding to a stressor, available resources to cope with other stressors or prolonged stress decrease, leaving individuals more vulnerable. From that perspective (Hobfoll, 1989, 2001), stress caused by the coronavirus crisis could threaten workers' individual resources. This loss of resources could subsequently decrease workers' capacity 
to respond to their work-related demands and stressors, thus impacting their job performance (Westman et al., 2005; Wright \& Cropanzano, 1998).

Finally, according to the Job Demands-Resources model (Bakker \& Demerouti, 2017), the association between demands, such as stress caused by the pandemic, and job performance could be mediated by psychological strain and exhaustion. Also, as stated above, stress has been associated with psychological distress, which has also been associated with decreased job performance (Berndt et al., 1998; Dewa \& Lin, 2000; Lim et al., 2000; Waghorn \& Chant, 2006). Thus, in accordance with these studies and theoretical models, the first hypothesis of the present study is (Fig. 1):

H1: Psychological distress will mediate the association between perceived stress and job performance.

\section{Health-Promoting Management Practices as a Moderator of the Association between Perceived Stress, Psychological Distress, and Job Performance}

Managers can have a significant influence on the psychological health of their employees. Indeed, previous studies have confirmed that managers positively or negatively influence employees' psychological health at work by acting on exposure to psychosocial risk factors, such as work overload or decision-making latitude, and by helping employees cope with work-related stress (Arnold, 2017; Kelloway \& Barling, 2010). Studies also indicate that concrete behaviors adopted by managers, i.e., health-promoting management practices (e.g., providing key information clearly about the tasks to be accomplished and recognizing employees' feelings by being

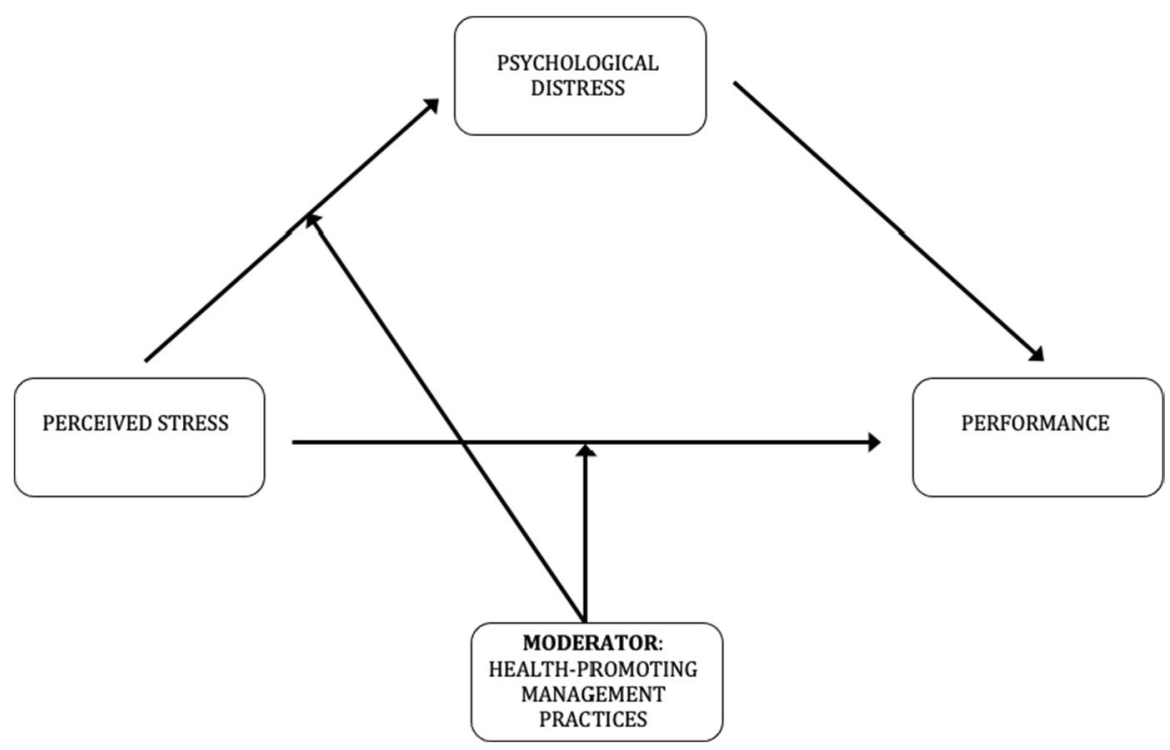

Fig. 1 Proposed model of moderated mediation 
empathetic), have a more important effect on employees' psychological health than a global leadership style, such as transformational leadership (Gilbert et al., 2017; Gilbreath \& Benson, 2004). However, to date, literature focusing on concrete managerial behaviors is less abundant.

During the COVID-19 pandemic, managers may play a critical role in understanding and responding to concerns about occupational health, safety and workers' well-being, since employees are under atypical and additional stress that can have a significant impact on their performance at work (Sinclair et al., 2020). Indeed, studies conducted in different crisis contexts have demonstrated that managers who show support and maintain communication can help protect workers' psychological health by reducing psychological strain (Biggs et al., 2014; Brooks et al., 2018; Greer \& Payne, 2014; Suzuki et al. 2014). These practices can also buffer workers' feeling of isolation related to working remotely (Gajendran \& Harrison, 2007; Henke et al., 2016; Montreuil \& Lippel, 2003; Tavares, 2017). Moreover, establishing a work structure by defining roles and expectations distinctly and showing consideration by inquiring into the level of comfort and well-being of employees can also help employees overcome their feelings of isolation (Hamouche, 2020; Marshall et al., 2007; Mulki and Jaramillo 2011; Watson, 2007).

Therefore, managers' health-promoting practices can help alleviate the stress their employees are experiencing, and contribute to a better workplace by promoting positive psychological health and functioning (Brooks et al., 2018; Sinclair et al., 2020; Tam et al., 2004). More concretely, results of previous studies have shown that training supervisors on how to better support their employees leads to positive outcomes on employee performance, retention, health, and well-being (Hammer et al., 2019; Odle-Dusseau et al., 2016). Also, other studies have noted the buffering effect of managerial support on the association between work demands, wellbeing, and job performance (Bakker \& Demerouti, 2017; O’Driscoll \& Brough, 2010). Finally, according to the Job Demands-Resources model (Bakker \& Demerouti, 2017), health-promoting management practices can act as a resource to buffer the negative effect of demands, for example, the stress caused by the pandemic, on psychological distress and job performance. Thus, it could be particularly useful for managers to adopt health-promoting management practices in order to mitigate the harmful effects of the stress caused by the pandemic. However, further studies are needed to empirically test this moderating effect. Accordingly, the second, third, and fourth hypotheses of the present study are (Fig. 1):

$\mathrm{H} 2$ : Health-promoting management practices will moderate the association between perceived stress and job performance. More specifically, managers' greater use of health-promoting management practices will lessen the association between perceived stress and job performance.

H3: Health-promoting management practices will moderate the association between perceived stress and psychological distress. More specifically, managers' greater use of health-promoting management practices will lessen the association between perceived stress and psychological distress.

H4: Health-promoting management practices will moderate the indirect association between perceived stress and job performance through psychological dis- 
tress. More specifically, managers' greater use of health-promoting management practices will lessen the indirect effect of perceived stress on job performance through psychological distress.

\section{Method}

This study was part of a larger longitudinal project that took place during the first wave of the COVID-19 crisis in Canada. The main purpose of the larger project was to better understand the impacts of the current crisis on several individual, social, and organizational indicators, as reported by a sample of workers. People who were 18 years old, resided in Canada, and had worked at least $20 \mathrm{~h}$ per week in any job and organization before the beginning of the COVID-19 crisis were eligible to complete the online survey. The data of the present study were collected as part of the second measurement time, between April 3 and 10, 2020.

\section{Procedure}

Participants were recruited in one of two ways: (a) paid and unpaid advertisements on Facebook, or (b) a panel of workers managed by Qualtrics. For the former, paid advertisements consisted of the eligibility criteria for the study and a link to the study's Facebook page and survey. Researchers on the project also shared the post on their personal pages and those of various community groups so that other users could share the post among their networks. For the Qualtrics panel, workers were recruited via a direct survey link provided by that organization. Those interested in participating in the survey clicked on a link provided in the advertisements, which directed them to an online survey on the Qualtrics platform. Prior to completing the survey, participants gave their consent and filled out demographic-related questions in order to verify their eligibility. The survey contained three attention checks that were imbedded in pre-existing scales to ensure that participants were attentive and to detect fraudulent responses. Those who failed these attention checks were excluded. After completing the survey, participants were provided with a mental health resource list and the opportunity to enter a raffle for a \$50 CAD Amazon gift card. This project was approved by Wilfrid Laurier University's ResearchEthics Board (REB \#6497).

\section{Participants}

As this study was interested in workers during the COVID-19 crisis, participants who were not working at least $10 \mathrm{~h}$ a week were excluded $(n=687)$. Analyses were thus performed on 435 adults $(n=435)$ living in Canada. Workers' average age was $42.49(S D=11.39)$, with a minimum age of 19 and a maximum of 71 . Workers were mostly women $(61.4 \%)$ and resided primarily in the provinces of Ontario $(47.8 \%)$, British Columbia (13.6\%), and Alberta (10.6\%). Moreover, participants were most likely to have completed a bachelor's degree $(40.2 \%)$ or a college or trade school 
diploma/certificate (20.2\%) and mainly worked as a professional or manager $(32.4 \%$ and $18.9 \%$, respectively). Finally, our sample was composed of participants from different industries, including health care (17.7\%), education (14.7\%), and services $(13.6 \%)$.

\section{Measures}

Sociodemographic Characteristics. Participants were asked to provide their age and job category (e.g., managers, professional). Also, they were asked to indicate their level of education and employment status and the industry in which they are employed.

Stress Perceived stress was measured with an adapted version of the four-item Perceived Stress Scale (PSS) (Cohen et al., 1983). The timeframe of the items was modified in order to better capture workers' perceived stress during the last few days in the context of the COVID-19 pandemic (e.g., In the LAST WEEK, how often have you felt confident about your ability to handle your personal problems? and In the LAST WEEK, how often have you felt difficulties were piling up so high that you could not overcome them?). Respondents indicated their experiences of stress on a 5-point Likert scale ranging from 0 (never) to 4 (very often). Before analysis, two items were reverse coded in such a way that a high score indicated greater stress. In order to be able to compare our sample's results with those of other studies (Nwachukwu et al., 2020), we considered a score greater than or equal to 1 as the norm for moderate to high perceived stress. Internal consistency of the scale was adequate $(\alpha=0.81)$.

Psychological Distress To measure psychological distress, The Patient Health Questionnaire (PHQ-4) was used (Kroenke et al., 2009). This short scale effectively assesses the presence of depression and anxiety symptoms. The timeframe of the four items was also modified to refer to the last week (e.g., Not being able to stop or control worrying and Little interest or pleasure in doing things), which was rated on a 4-point Likert scale $(0=$ not at all; $3=$ nearly every day). A mean score of the four items was calculated. A mean score equal to or greater than $1.5 / 3$ was considered as the clinical threshold for anxiety and depression (Kroenke et al., 2009). Cronbach's alpha of the PHQ-4 was excellent $(\alpha=0.92)$.

Job Performance Job performance was assessed with the short form of the Health and Work Performance Questionnaire (HPQ) (Kessler et al., 2003). This two-item scale was used to measure the worker's actual performance in relation to their possible performance, which refers to workers' performance in a job similar to theirs. Participants were asked to answer the following questions on a scale ranging from 1 (worst performance) to 10 (top performance): How would you rate the USUAL performance of most workers in a job similar to yours? and How would you rate your overall job performance on the days you worked during the PAST WEEK? A relative performance score was computed by dividing the actual performance by 
the performance of most workers at the same job. A higher score indicates better performance.

Health-Promoting Management Practices. To assess health-promoting management practices, 10 management practices that promote psychological health at work were retrieved from St-Hilaire et al.'s (2018) qualitative study (e.g., Provided me with emotional support and Gave clear instructions for tasks). Workers were asked to indicate, on a 5-point Likert scale $(1=$ never; $5=$ very often $)$, which behaviors were demonstrated by their main supervisor in the last week. A higher score indicates the presence of more management practices that promote psychological health at work. An exploratory factor analysis (principal axis factoring) was carried out with an oblimin rotation and reveals a single-factor solution (only one factor had an eigenvalue ' 1 ) that explained $61.77 \%$ of the total variance. The 10 -item scale had very good internal consistency $(\alpha=0.94)$. The complete questionnaire is presented in the Appendix.

\section{Statistical Analyses}

SPSS v.27 (IBM) was used for statistical analyses. Preliminary analyses revealed that missing data represent less than $5 \%$ of the data (between 0.9 and $3.6 \%$ ) and were distributed randomly. Thus, missing data were not imputed and listwise deletion was used. Also, all study variables were distributed normally with skewness and kurtosis indices between the range of -3 and +3 (Tabachnick \& Fidell, 2013). Correlational analyses were used to examine the associations between the study variables. Mediation and moderation analyses were performed using Hayes' (2013) PROCESS macro (http://www.processmacro.org/) for SPSS, which conducts linear or logistic regression to estimate mediation and moderation effects. The PROCESS macro makes it possible to use bootstrap as well as correct any heteroscedasticity problems. Each analysis used 5,000 bootstrapping resamples and bias-corrected 95\% confidence intervals (CI). As suggested by Hayes (2013), mediation effects and moderating effects were first examined separately using models 4 and 1 of the PROCESS macro, respectively. Subsequently, moderated mediation analyses were conducted using Hayes' PROCESS macro model 8. In order to simplify interpretation, variables were standardized ( $Z$ scores) prior to conducting the analyses. Standardized beta coefficients $(\beta)$ are thus presented throughout the article.

\section{Results}

\section{Correlational Analyses}

Descriptive statistics and correlations among the study variables are presented in Table 1. Results indicate a high level of stress and psychological distress among study participants. Indeed, $84.4 \%$ of participants indicated a moderate to high level of perceived stress (PSS $>1$ ), while $36.3 \%$ were considered to have moderate 
Table 1 Correlation among study variables

\begin{tabular}{lllllll}
\hline & $M$ & $S D$ & 1 & 2 & 3 & 4 \\
\hline 1. Perceived stress & 1.72 & 0.81 & & & \\
2. Psychological distress & 1.04 & 0.90 & $.771^{* *}$ & & \\
3. Performance & 0.98 & 0.27 & $-.232^{* *}$ & $-.297^{* *}$ & \\
$\begin{array}{l}\text { 4. Health-promoting manage- } \\
\quad\end{array}$ & 3.32 & 1.00 & $-.197 * *$ & $-.157^{* *}$ & .028 \\
\hline
\end{tabular}

$* * p<0.01$.

to severe psychological distress (PHQ-4>1.5). The present study's results also revealed that perceived stress was positively associated with psychological distress, but negatively associated with health-promoting management practices and job performance. Psychological distress was also negatively correlated with the two latter variables.

\section{Mediation Analysis}

Figure 2 presents standardized beta regression coefficients and standard errors for each path in the mediation analysis. Perceived stress was positively associated with psychological distress (path a) while psychological distress was negatively associated with job performance (path b). The total effect of perceived stress on job performance was negative and significant (path c). However, when psychological distress was entered into the model, the relationship between perceived stress and job performance decreased and became not significant (direct effect: path $c^{\prime}$ ). Thus, psychological distress fully mediated the relationship between perceived stress and job performance (Frazier et al., 2004). Mediation analysis

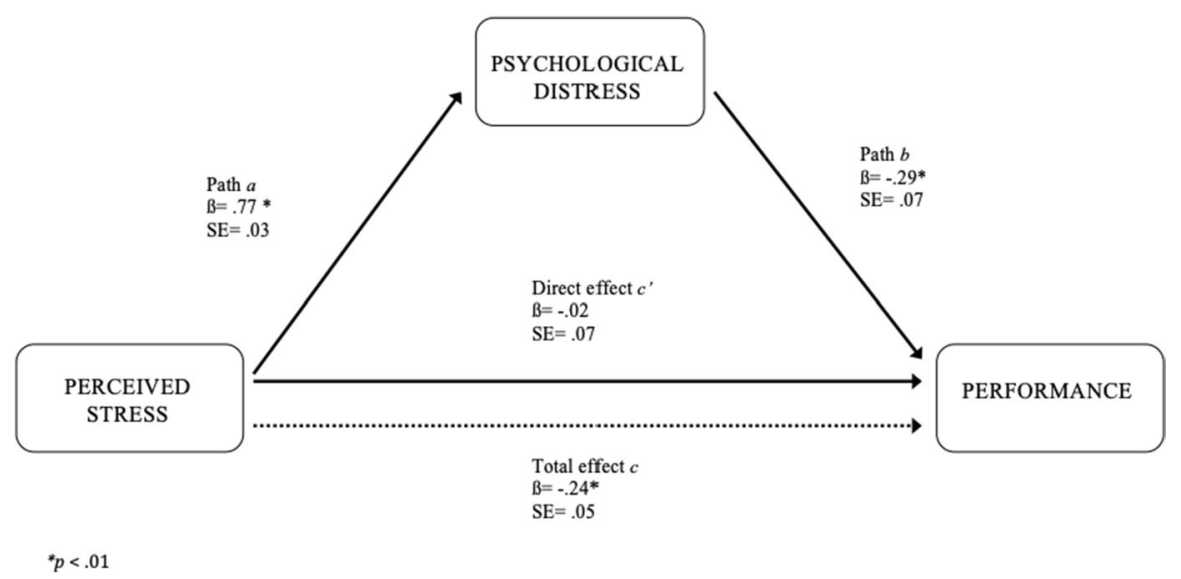

Fig. 2 Mediation analyses of the association between perceived stress and performance through psychological distress 
results indicated a significant indirect effect of perceived stress on performance through psychological distress $(\beta=-0.22, S E=0.06,95 \%$ CI $[-0.33,-0.11])$.

\section{Moderation Analysis}

The results of the moderation analyses are presented in Table 2. Results concerning job performance are detailed first, followed by results concerning psychological distress. For job performance, results indicated there was no association with health-promoting management practices. However, a significant two-way interaction was found between perceived stress and health-promoting management practices. More precisely, as shown in Fig. 3, perceived stress and job performance were negatively associated when health-promoting management practices were low $(-1 S D$; $\beta=-0.35, S E=0.08,95 \%$ CI $[-0.50,-0.20])$ or average $(M ; \beta=-0.21, S E=0.05$, 95\% CI $[-0.31,-0.12])$. However, at a higher level of health-promoting management practices, the association between perceived stress and job performance was not significant $(+1 S D ; \beta=-0.08, S E=0.06,95 \%$ CI $[-0.19,0.04])$.

As for psychological distress, findings indicated that it was not associated with health-promoting management practices. However, the two-way interaction between perceived stress and health-promoting management practices was statistically significant. More specifically, as presented in Fig. 4, the association between perceived stress and psychological distress was positive and significant but its strength diminished as health-promoting management practices increased (low HMP ( $-1 S D$; $\beta=0.81, S E=0.04,95 \%$ CI $[0.73,0.89])$, average $\operatorname{HMP}(M ; \beta=0.75, S E=0.03,95 \%$ CI $[0.70,0.81])$, high HMP $(+1 S D ; \beta=0.70, S E=0.04,95 \%$ CI $[0.62,0.78]))$.

Table 2 Moderating effects of health-promoting management practices on the association between perceived stress and performance and psychological distress

\begin{tabular}{lllll}
\hline & $\beta$ & $S E$ & $L L C I$ & ULCI \\
\hline Performance & & & & \\
Constant & .04 & .05 & -.05 & .13 \\
Perceived stress (PS) & $-.21^{* *}$ & .05 & -.31 & -.12 \\
Health-promoting & -.03 & .05 & -.13 & .07 \\
$\quad$ management practices & & & & \\
$\quad$ (HMP) & & & & \\
PS X HMP & $.14^{* *}$ & .05 & .05 & .23 \\
Psychological distress & & & & \\
Constant & $-.11^{* *}$ & .03 & -.18 & -.05 \\
Perceived stress (PS) & $.75^{* *}$ & .03 & .70 & .81 \\
Health-promoting & -.00 & .03 & -.07 & .07 \\
$\quad$ management practices & & & & \\
$\quad$ (HMP) & & & & \\
PS X HMP & $-.06^{*}$ & .03 & -.11 & -.00 \\
\hline
\end{tabular}

$L L C I$, lower level of $95 \%$ confidence interval; $U L C I$, upper level of $95 \%$ confidence interval.

$* p<0.05, * * p<0.01$. 


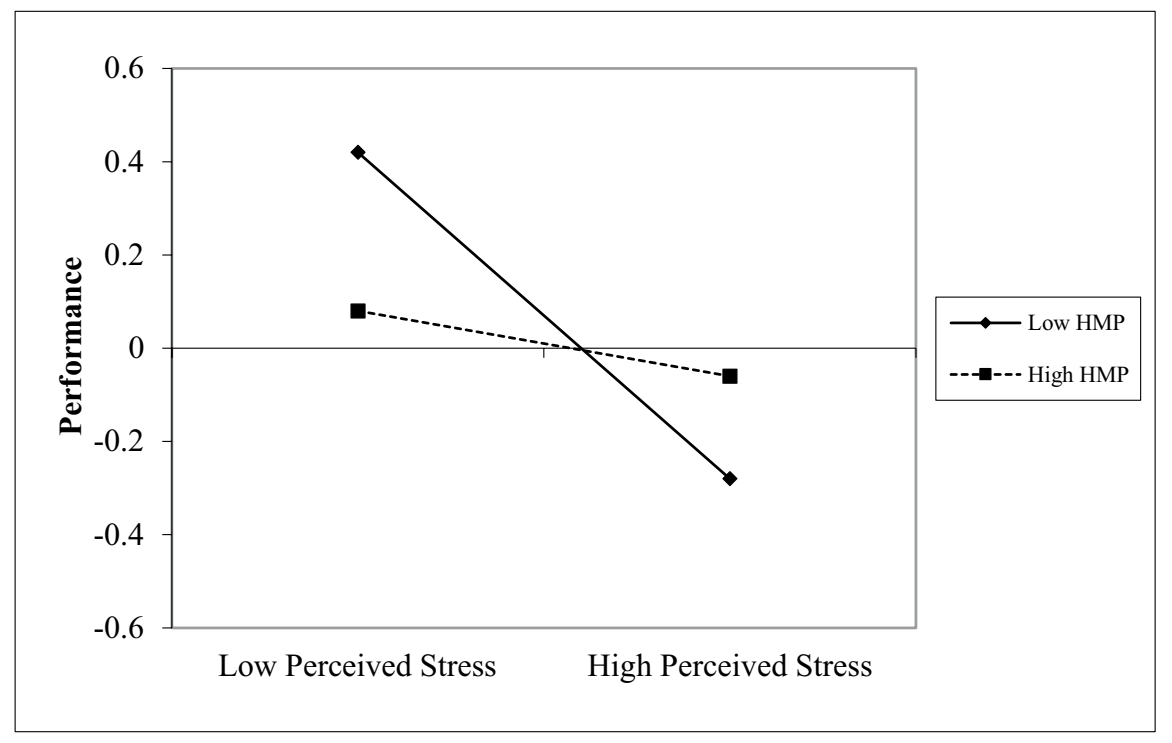

Note: The figures show predicted regression lines for one standard deviation below (low) and one standard deviation above (high) the mean of HMP. Variables are standardized ( $Z$ scores).

Fig. 3 The moderating effect of health-promoting management practices (HMP) in the association between perceived stress and performance

\section{Moderated Mediation Analysis}

The mediating and moderating analyses conducted indicated that psychological distress mediated the association between perceived stress and job performance, whereas health-promoting management practices moderated the path between perceived stress and job performance as well as the path between perceived stress and psychological distress. In order to test the presence of a moderated mediation, a final analysis was carried out. Thus, tests were performed to determine the mediating effect of psychological distress in the relationship between perceived stress and job performance when health-promoting management practices were considered as a moderator. Results indicated that the indirect effect of highest order product was significant $(\beta=0.01, S E=0.01,95 \%$ CI [0.00, 0.03]). More specifically, the indirect effect of perceived stress on performance through psychological distress was negative and significant for all levels of health-promoting management practices reported (see Table 3). However, as the level of health-promoting management practices increased, the indirect effect of 


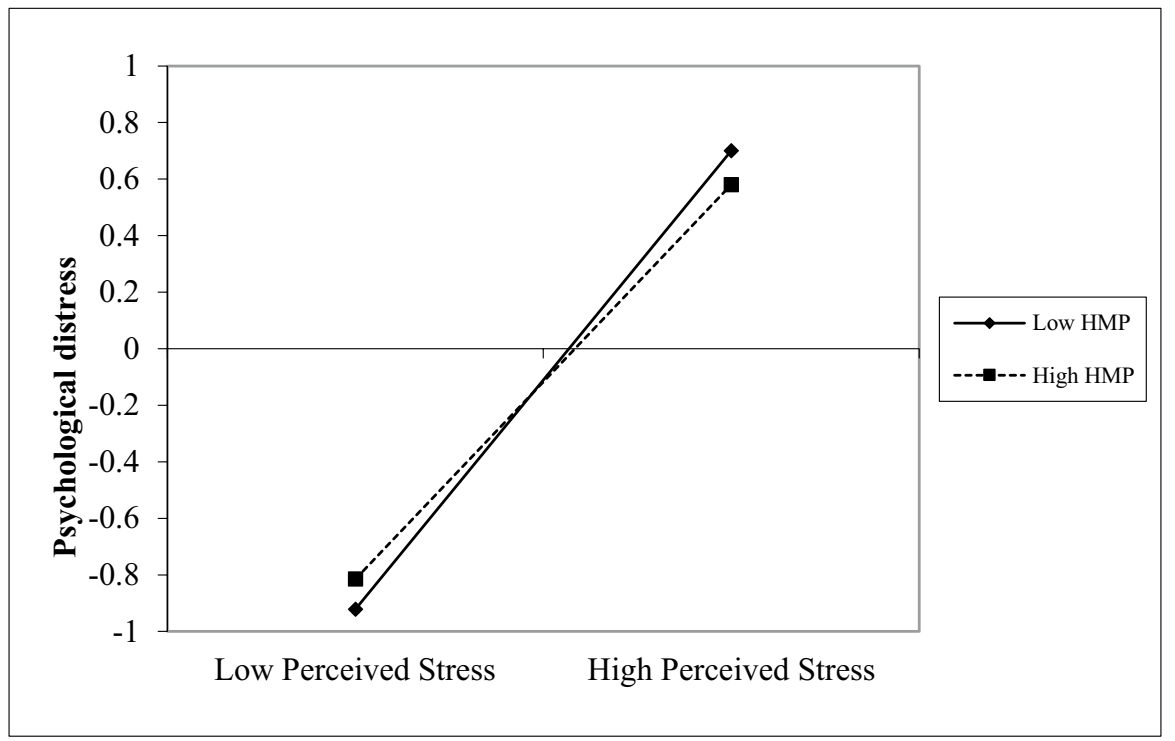

Note: The figures show predicted regression lines for one standard deviation

below (low) and one standard deviation above (high) the mean of HMP.

Variables are standardized ( $\mathrm{Z}$ scores).

Fig. 4 The moderating effect of health-promoting management practices (HMP) in the association between perceived stress and psychological distress

Table 3 Conditional indirect effect of perceived stress on performance via psychological distress for values of the moderators

\begin{tabular}{llllll}
\hline Moderator & & $\begin{array}{l}\text { Conditional } \\
\text { indirect effect }\end{array}$ & $S E$ & LLCI & ULCI \\
\hline Health-promoting management practices (HMP) & Low HMP & $-.21^{*}$ & .06 & -.33 & -.10 \\
& Average HMP & $-.20^{*}$ & .06 & -.31 & -.09 \\
& High HMP & $-.18^{*}$ & .05 & -0.29 & -.09 \\
\hline
\end{tabular}

$L L C I$, lower level of confidence interval; $U L C I$, upper level of confidence interval; $H M P$, health-promoting management practices.

$* p<0.05$.

perceived stress on performance through psychological distress decreased. This model explains $10.1 \%$ of job performance variance and $56.8 \%$ of psychological distress variance. 


\section{Discussion}

The results of the present study first reveal a high level of stress and psychological distress among study participants during the first wave of the COVID-19 pandemic. Indeed, most participants indicated a moderate to high level of perceived stress, while a third of participants were considered to have moderate to severe psychological distress. These scores are very similar to those found by Nwachukwu et al. (2020), who used a longer 14-item version of the Perceived Stress Scale (PSS) and The Patient Health Questionnaire (PHQ-9) among Canadians, and found proportions of $85.7 \%$ and $44.1 \%$, respectively. In this context, the first objective of this study was to investigate the relationship between this perceived stress and psychological distress, and job performance among workers. When intense and prolonged, stress can have a significant impact on individuals and their organization and it is essential to identify solutions that alleviate its deleterious impact (Lim et al., 2000; Waghorn \& Chant, 2006). Consistent with previous literature, correlational analyses indicated a positive association between perceived stress and psychological distress as well as a negative association between perceived stress and job performance (Dewa \& Lin, 2000; Gilboa et al., 2008; Grebner et al., 2003; Wright \& Cropanzano, 1998). Results also indicated that psychological distress fully mediates the relationship between perceived stress and job performance. Consequently, as the level of perceived stress increases, employees tend to feel more psychologically distressed, which then is associated with a decrease in their performance at work. Thus, psychological distress is one of the mechanisms explaining the influence of perceived stress on job performance. In line with these results, several studies gathered in a systematic review have also exemplified the deleterious effects of work-related stress on psychological health, more specifically in the context of a crisis (Berger et al. 2012), such as the coronavirus pandemic. The present study expands our knowledge on this question by demonstrating that a global measure of stress is associated with employees' psychological health, which in turn seems to impact their job performance. Hence, stress appears to be transferred to the work domain and influences workers' functioning. While a certain amount of stress may be adaptive and energizing, intense stress associated with psychological distress negatively affects job performance. Acting on stressors therefore has effect not only on the psychological health of workers, but also on their performance. More specifically, it decreases psychological distress as well as increases workers' performance. Interventions such as flexible work schedules, participation in decision-making, stress management programs, and social support provision could be useful approaches for altering the deleterious effect of stress on workers' psychological health and performance (Elkin \& Rosch, 1990; Sonnentag \& Frese, 2003). The specific context of the COVID-19 pandemic highlights the importance of caring for workers' psychological health during times of crisis. In fact, it is essential that employees take care of themselves and their families while they continue to hold their job (Hamouche, 2020).

As a second objective, this study also tested the moderating effects of management practices aimed at promoting psychological health on the relationship between perceived stress, psychological distress, and job performance. First, 
moderation analyses indicated that the association between perceived stress and job performance was significantly affected by health-promoting management practices. Indeed, as these management practices increased, the negative association between perceived stress and job performance decreased and became not significant. This finding suggests that high use of management practices aimed at increasing employees' psychological health at work (e.g., respond to employees' needs and requests promptly; monitor progress on files and deadlines) can alleviate the negative effect of perceived stress on job performance. Results also indicated that the association between perceived stress and psychological distress was significantly impacted by health-promoting management practices. Indeed, although the positive association between perceived stress and psychological distress remained significantly positive at all levels of the moderator, it decreased as management practices aimed at promoting psychological health increased. Thus, through their role, managers could alleviate employees' distress, particularly in the context of a crisis such as COVID-19 (Brooks et al., 2020; Tam et al., 2004). As this unprecedented situation has necessarily led to drastic changes in workplaces, such as teleworking, it is essential to support and train managers so that they can develop the necessary skills and adopt the appropriate behaviors to promote their employees' psychological health and job performance. Health-promoting management practices focusing on consideration (e.g., asked about my physical and mental health) and structure (e.g., gave clear instructions for tasks) have been recognized as particularly efficient for this purpose. In this regard, several studies have pointed out positive outcomes of training managers to implement health-promoting management practices that, for example, demonstrate support (Hammer et al., 2019; Odle-Dusseau et al., 2016).

Finally, the results of the present study revealed a significant moderated mediation, with the indirect effect of perceived stress on job performance through psychological distress decreasing as health-promoting management practices increased. Thus, to some extent, managers may help to break the stress-psychological distress-job performance loop (Väänänen et al., 2003). However, this result should be considered with caution, since the moderated mediation effect was rather small $(\beta=0.01)$. Also, the hypothesized model explained only a small proportion of the variance in job performance $(10 \%)$. Thus, without denying the important role of managers, interventions at the individual, group, and organizational levels also need to be considered to promote the psychological health of workers and their performance (Nielsen et al., 2017). Psychological health at work is a shared responsibility and requires the participation of different stakeholders (e.g., employees, managers, leaders).

\section{Limitations and Future Studies}

The present study has some limitations that should be mentioned. First, its cross-sectional nature prevents us from concluding that there is any cause-andeffect relationship. In relation to this, it is impossible to confirm the direction of the relationship between perceived stress, psychological distress, and job 
performance. Indeed, Leclerc et al. (2014) have suggested the presence of a bidirectional association between psychological health and performance. Therefore, not only could psychological health improve performance at work, but high job performance could also have a positive impact on well-being. In future longitudinal studies, it would be important to examine these bidirectional associations using a cross-lagged analysis. Second, stress was assessed with a perceptual subjective measure. Since Oumohand et al. (2020) have suggested that subjective and physiological measures are linked to different dimensions of chronic stress, future research should consider a more objective measure of stress, such as hair cortisol concentration. Third, all participants were Canadians, which may limit the generalizability of the results. Finally, our measure of health-promoting management practices only includes a limited number of practices that are usually recognized as effective in a remote and crisis context (namely practice focusing on consideration, support, and structure). However, St-Hilaire et al. (2018) have identified an exhaustive list of 92 management practices that can promote psychological health at work. Additional research should consider a greater number of health-promoting management practices and investigate their particular effect on employees' psychological health and job performance. Also, since our measure of health-promoting management practices has not been validated, further studies are needed in this regard.

\section{Conclusion}

To conclude, the results of the present study indicate that, in the context of the COVID-19 pandemic, a high level of stress can be associated with psychological distress, which can in turn be associated with decreased job performance. However, it appears that managers who implement health-promoting management practices that focus on establishing work structure, demonstrating consideration, and showing support help buffer the impact of perceived stress on employees' psychological health and performance at work. To our knowledge, the present study is the first to investigate this moderating association. The results suggest numerous avenues for future research and interventions. Indeed, interventions aimed at reducing stress and promoting job performance at work would be improved by involving managers. However, more research is needed to identify specific behaviors that should be adopted by managers to achieve these outcomes.

\section{Appendix. Health-promoting management practices questionnaire}

Below, you'll find a list of behaviors supervisors can adopt to promote the psychological health of their employees.

Please indicate how often your main supervisor adopted these behaviors in the LAST WEEK. If you do not have a supervisor, please indicate N/A. 


\begin{tabular}{llllll}
\hline Never & Rarely & Sometimes & Often & Very often & N/A \\
\hline 1 & $\mathbf{2}$ & $\mathbf{3}$ & $\mathbf{4}$ & $\mathbf{5}$ & $\mathbf{6}$ \\
\hline
\end{tabular}

My main supervisor...

1. Demonstrated flexibility in the implementation of rules.

2. Notified me of their availability.

3. Asked about my physical and mental health.

4. Asked about workload and problems.

5. Provided me with emotional support.

6. Responded to my needs and requests promptly.

7. Gave clear instructions for tasks.

8. Provided material and resources necessary to complete tasks.

9. Monitored progress on files and deadlines.

10. Communicated in a straightforward manner.

Acknowledgements The authors would like to thank Hugues Leduc, department research agent and statistician, for his dedicated participation in our discussions regarding our statistical analysis, and Karen Grislis for her rigorous editing services.

Author Contribution All the contributors to the study are considered authors because they made substantial contributions to (1) conception and design of the study and interpretation of data; (2) critical revision of the article for important intellectual content; and (3) final approval of the version to be published, bringing their own perspective and body of knowledge. All authors have revised and accepted the final version of the manuscript.

Funding The authors declare that this study received funding from Wilfrid Laurier University, the Social Science and Humanities Research Council of Canada's General Research Fund, and the National Bank of Canada. The funders did not take part in the study design, data collection, analysis, or interpretation and in the writing of this article or the decision to submit this article for publication.

Data Availability The raw data supporting the conclusions of this article will be made available by the authors, without undue reservation.

Materials Availability The raw data supporting the conclusions of this article will be made available by the authors, without undue reservation.

Code Availability Not applicable.

\section{Declarations}

Ethics Approval Ethics approval (REB \#6497).

Consent to Participate All the participants gave their consent prior to take part in the study.

Consent for Publication All the contributors gave their consent on the manuscript for publication.

Conflict of Interest The authors declare no competing interests. 


\section{References}

Amirkhan, J. H. (2020). Stress overload in the spread of coronavirus. Anxiety, Stress \& Coping, 34(2), 121-129. https://doi.org/10.1080/10615806.2020.1824271

Arnold, K. A. (2017). Transformational leadership and employee psychological well-being: A review and directions for future research. Journal of Occupational Health Psychology, 22(3), 381-393. https:// doi.org/10.1037/ocp0000062

Bakker, A. B., \& Demerouti, E. (2017). Job demands-resources theory: Taking stock and looking forward. Journal of Occupational Health Psychology, 22(3), 273-285. https://doi.org/10.1037/ocp00 00056

Bao, Y., Sun, Y., Meng, S., Shi, J., \& Lu, L. (2020). 2019-nCoV epidemic: Address mental health care to empower society. The Lancet, 395(10224), 37-38. https://doi.org/10.1016/S0140-6736(20)30309-3

Berger, W., Coutinho, E. S., Figueira, I., Marques-Portella, C., Luz, M. P., Neylan, T. C., Marmar, C. R., \& Mendlowicz, M. V. (2012). Rescuers at risk: A systematic review and meta-regression analysis of the worldwide current prevalence and correlates of PTSD in rescue workers. Social Psychiatry and Psychiatric Epidemioly. 47(6), 1001-1011. https://doi.org/10.1007/s00127-011-0408-2

Berndt, E. R., Finkelstein, S. N., Greenberg, P. E., Howland, R. H., Keith, A., Rush, A. J., Russell, J., \& Keller, M. B. (1998). Workplace performance effects from chronic depression and its treatment. Journal of Health Economics, 17(5), 511-535. https://doi.org/10.1016/s0167-6296(97)00043

Biggs, A., Brough, P., \& Barbour, J. P. (2014). Exposure to extraorganizational stressors: Impact on mental health and organizational perceptions for police officers. International Journal of Stress Management, 21(3), 255-282. https://doi.org/10.1037/a0037297

Biron, C., St-Hilaire, F., Baril-Gingras, G., Paradis, M., Chabot, S., Lefebvre, R., Ivers, H., Vézina, M., Fournier, P., Gilbert-Ouimet, M. \& Brisson, C. (2016). Conditions facilitant l'appropriation de démarches préventives en santé psychologique au travail par les gestionnaires. RR-921, IRSST.

Borman, W. C., \& Motowildo, S. J. (1993). Expanding the criterion domain to include elements of contextual performance. In N. Schmitt \& W. C. Borman (Eds.), Personnel selection in organizations (pp. 71-98). Jossey-Bass.

Brooks, S., Amlôt, R., Rubin, G. J., \& Greenberg, N. (2018). Psychological resilience and post-partum growth in disaster-exposed organisations: Overview of the literature. Journal of the Royal Army Medical Corps, 166(1), 52-56. https://doi.org/10.1136/jramc-2017-000876

Brooks, S., Webster, R. K., Smith, L. E., Woodland, L., Wessely, S., Greenberg, N., \& Rubin, G. J. (2020). The psychological impact of quarantine and how to reduce it: Rapid review of the evidence. The Lancet, 395(10227), 912-920. https://doi.org/10.1016/S0140-6736(20)30460-8

Chan, A. O., \& Huak, C. Y. (2004). Psychological impact of the 2003 severe acute respiratory syndrome outbreak on health care workers in a medium size regional general hospital in Singapore. Occupational Medecine, 54(3), 190-196. https://doi.org/10.1093/occmed/kqh027

Cohen, S., Karmarck, T. \& Mermelstein, R. (1983). A global measure of perceived stress. Journal of Health and Social Behavior, 24(4), 385-396. http://www.jstor.org/stable/2136404 .

Crouter, A. C. (1984). Spillover from family to work: The neglected side of the work-family interface. Human Relations, 37(6), 425-441. https://doi.org/10.1177/001872678403700601

Dewa, C. S., \& Lin, E. (2000). Chronic physical illness, psychiatric disorder and disability in the workplace. Social Science \& Medicine, 51(1), 41-50. https://doi.org/10.1016/S0277-9536(99)00431-1

Drapeau, A., Marchand, A., \& Beaulieu-Prévost, D. (2011). Epidemiology of psychological distress. In L. L'Abate (Ed.), Mental illnesses-understanding, prediction and control (pp. 105-135). InTech Open.

Elkin, A. J., \& Rosch, P. J. (1990). Promoting mental health at the workplace: The prevention side of stress management. Occupational Medecine, 5(4), 739-754.

Fink, G. (2016). Stress, definitions, mechanisms, and effects outlined: Lessons from anxiety. In Stress: Concepts, cognition, emotion, and behavior, (p. 3-11), Academic Press.

Folkman, S., \& Lazarus, R. S. (1990). Coping and emotion. In N. L. Stein, B. Leventhal, \& T. Trabasso (Eds.), Psychological and biological approches to emotion (pp. 313-332). Erlbaum.

Ford, M. T., Heinen, B. A., \& Langkamer, K. L. (2007). Work and family satisfaction and conflict: A meta-analysis of cross-domain relations. Journal of Applied Psychology, 92(1), 57-80. https://doi. org/10.1037/0021-9010.92.1.57

Frazier, P. A., Tix, A. P., \& Barron, K. E. (2004). Testing moderator and mediator effects in counseling psychology research. Journal of Counseling Psychology, 51(1), 114-134. https://doi.org/10.1037/ 0022-0167.51.1.115 
Gajendran, R. S., \& Harrison, D. A. (2007). The good, the bad, and the unknown about telecommuting: Meta-analysis of psychological mediators and individual consequences. Journal of Applied Psychology, 92(6), 1524-1541. https://doi.org/10.1037/0021-9010.92.6.1524

Gilbert, M.-H., Dagenais-Desmarais, V., \& St-Hilaire, F. (2017). Transformational leadership and autonomy support management behaviors: The role of specificity in predicting employees' psychological health. Leadership \& Organization Development Journal, 38(2), 320-332. https://doi. org/10.1108/LODJ-08-2015-0173

Gilboa, S., Shirom, A., Fried, Y., \& Cooper, C. (2008). A meta-analysis of work demand stressors and job performance: Examining main and moderating effects. Personnel Psychology, 61(2), 227271. https://doi.org/10.1111/j.1744-6570.2008.00113.x

Gilbreath, B., \& Benson, P. G. (2004). The contribution of supervisor behaviour to employee psychological well-being. Work \& Stress, 18(3), 255-266. https://doi.org/10.1080/026783704123313 17499

Grebner, S., Norbert, K. S., Faso, L. L., Gut, S., Kälin, W., \& Elfering, A. (2003). Working conditions, well-being, and job-related attitudes among call center agents. European Journal of Work and Organizational Psychology, 12(4), 341-365. https://doi.org/10.1080/13594320344000192

Greer, T. W., \& Payne, S. C. (2014). Overcoming telework challenges: Outcomes of successful telework strategies. The Psychologist Manager Journal, 17(2), 87-111. https://doi.org/10.1037/ mgr0000014

Hammer, L. B., Wan, W. H., Brockwood, K., Bodner, T., \& Mohr, C. D. (2019). Supervisor support training effects on veterans in the workplace: Effects on health and work outcomes. Journal of Applied Psychology, 104, 52-69. https://doi.org/10.1037/ap10000354

Hamouche, S. (2020). COVID-19 and employees' mental health: Stressors, moderators and agenda for organizational actions. Emerald Open Research, 2(15), 1-15. https://doi.org/10.35241/emeraldope nres. 13550.1

Hayes, A. F. (2013). Introduction to mediation, moderation, and conditional process analysis: A regression-based approach. Guilford Press.

Henke, R. M., Benevent, R., Schulte, P., Rinehart, C., Crighton, K. A., \& Corcoran, M. (2016). The effects of telecommuting intensity on employee health. American Journal of Health Promotion, 30(8), 604-612. https://doi.org/10.4278/ajhp.141027-QUAN-544

Hobfoll, S. E. (1989). Conservation of ressources: A new attempt at conceptualizing stress. American Psychologist, 44, 513-524. https://doi.org/10.1037/0003-066X.44.3.513

Hobfoll, S. E. (2001). The influence of culture, community, and nested-self in the stress process: Advancing conservation of ressources theory. Applied Psychology: An International Review, 50(3), 337421. https://doi.org/10.1111/1464-0597.00062

Jamal, M. (2007). Job stress and job performance controversy revisited: An empirical examination in two countries. International Journal of Stress Management, 14(2), 175-187. https://doi.org/10.1037/ 1072-5245.14.2.175

Kelloway, E. K., \& Barling, J. (2010). Leadership development as an intervention in occupational health psychology. Work \& Stress, 24(3), 260-279. https://doi.org/10.1080/02678373.2010.518441

Kessler, R. C., Barber, C., Beck, A. L., Berglund, P. A., Cleary, P. D., McKenas, D., Pronk, N. P., Simon, G. E., Stang, P. E., Üstün, T. B., \& Wang, P. S. (2003). The World Health Organization Health and Work Performance Questionnaire (HPQ). Journal of Occupationnal and Environmental Medecine, 45(2), 156-174. https://doi.org/10.1097/01.jom.0000052967.43131.51

Kroenke, K., Spitzer, R. L., Williams, J. B., \& Löwe, B. (2009). An ultra-brief screening scale for anxiety and depression: The PHQ-4. Psychosomatics, 50(6), 613-621. https://doi.org/10.1016/S00333182(09)70864-3

Kuoppala, J., Lamminpää, A., Liira, J., \& Vainio, H. (2008). Leadership, job well-being, and health effects-A systematic review and a meta-analysis. Journal of Occupational and Environmental Medicine, 50(8), 904-915. https://doi.org/10.1097/JOM.0b013e31817e918d

Lazarus, R. S. (1966). Psychological stress and the coping process. McGraw-Hill.

Leclerc, J. S., Boudrias, J. S., \& Savoie, A. (2014). La santé psychologique et la performance au travail : Des liens longitudinaux bidirectionnels? Le Travail Humain, 77(4), 251-372. https://doi.org/ 10.3917/th.774.0351

LePine, J. A., Podsakoff, N. P., \& LePine, M. A. (2005). A meta-analytic test of the challenge stressorhindrance stressor framework: An explanation for inconsistent relationship among stressors and performance. Academy of Management Journal, 48(5), 764-775. https://doi.org/10.5465/amj.2005. 18803921 
Lim, D., Sanderson, K., \& Andrews, G. (2000). Lost productivity among full-time workers with mental disorders. The Journal of Mental Health Policy and Economics, 3(3), 139-146. https://doi.org/10. 1002/mhp.93

Lim, S., \& Tai, K. (2014). Family incivility and job performance: A moderated mediation model of psychological distress and core self-evaluation. Journal of Applied Psychology, 99(2), 351-359. https:// doi.org/10.1037/a0034486

Marchand, A. (2004). Travail et santé mentale: une perspective multiniveau des déterminants de la détresse psychologique. [Doctoral dissertation, Université de Montréal]. Papyrus. http://hdl.handle. net/1866/14848

Marshall, G. W., Michaels, C. E., \& Mulki, J. P. (2007). Workplace isolation: Exploring the construct and its measurement. Psychology \& Marketing, 24(3), 195-223. https://doi.org/10.1002/mar.20158

Massé, R., Poulin, C., Dassa, C., Lambert, J., Bélair, S., \& Battaglini, A. (1998). Élaboration et validation d'un outil de mesure de la détresse psychologique dans une population non clinique de Québécois francophones. Canadian Journal of Public Health, 89(3), 183-187. https://doi.org/10.1007/BF034 04471

Mennino, S. F., Rubin, B. A., \& Brayfield, A. (2005). Home-to-job and job-to-home spillover: The impact of company policies and workplace culture. The Sociological Quarterly, 46(1), 107-135. https://doi. org/10.1111/j.1533-8525.2005.00006.x

Montreuil, S., \& Lippel, K. (2003). Telework and occupational health: A Quebec empirical study and regulatory implications. Safety Science, 41(4), 339-358. https://doi.org/10.1016/S0925-7535(02) 00042-5

Motowildo, S. J., Packard, J. S., \& Manning, M. R. (1986). Occupational stress: Its cause and consequences for job performance. Journal of Applied Psychology, 71(4), 618-629. https://doi.org/10. 1037/0021-9010.71.4.618

Mulki, J. P., \& Jaramillo, F. (2011). Workplace isolation: Salespeople and supervisors in USA. The International Journal of Human Resource Management, 22(04), 902-923. https://doi.org/10.1080/09585 192.2011.555133

Nickell, L. A., Crighton, E. J., Tracy, C. S., Al-Enazy, H., Bolaji, Y., Hanjrah, S., Hussain, A., Makhlouf, S., \& Upshur, R. E. G. (2004). Psychosocial effects of SARS on hospital staff: Survey of a large tertiary care institution. Canadian Medical Association Journal, 170(5), 793-798. https://doi.org/ 10.1503/cmaj.1031077

Nielsen, K., Nielsen, M. B., Ogbonnaya, C., Känsälä, M., Saari, E., \& Isaksson, K. (2017). Workplace resources to improve both employee well-being and performance: A systematic review and metaanalysis. Work \& Stress, 31(2), 101-120. https://doi.org/10.1080/02678373.2017.1304463

Nwachukwu, I., Nkire, N., Shalaby, R., Hrabok, M., Vuong, W., Gusnowski, A., Surood, S., Urichuk, L., Greenshaw, A. J., \& Agyapong, V. I. O. (2020). COVID-19 pandemic: Age-related differences in measures of stress, anxiety and depression in Canada. Environmental Research and Public Health, 17(17), 1-10. https://doi.org/10.3390/ijerph17176366

Odle-Dusseau, H. N., Hammer, L. B., Crain, T. L., \& Bodner, T. E. (2016). The influence of supportive supervisor training on employee job performance and attitudes: An organizational work-family intervention. Journal of Occupational Health Psychology, 21(3), 296-308. https://doi.org/10.1037/ a0039961

O’Driscoll, M. P. \& Brough, P. (2010). Work organization and health. In S. Leka \& J. Houdmont (Eds.), Occupational Health Psychology. John Wiley \& Sons.

Oumohand, S. E., Ward, D. D., Boenniger, M. M., Merten, N., Kirschbaum, C., \& Breteler, M. M. B. (2020). Perceived stress but not hair concentration is related to adult cognitive performance. Psychoneuroendocrinology, 121(104810), 1-8. https://doi.org/10.1016/j.psyneuen.2020.104810

Pacheco, T., Coulombe, S., Khalil, C., Meunier, S., Doucerin, M., Auger, É., \& Cox, E. (2020). Job security and the promotion of workers wellbeing in the midst of the COVID-19 pandemix: A study with Canadian workers one to two weeks after the initiation of social distancing measures. International Journal of Wellbeing, 10(3), 58-76. https://doi.org/10.5502/ijw.v10i3.1321

Préville, M. (1995). Étude de la validité et de la fiabilité de la mesure de détresse psychologique utilisée dans l'Enquête Santé Québec. In: Université de Montréal: Les cahiers du GRIS, T95-01.

Rich, B. L., LePine, J., \& Crawford, E. R. (2010). Job engagement: Antecedents and effects on job performance. Academy of Management Journal, 53(3), 617-635. https://doi.org/10.5465/amj.2010.51468 988

Selye, H. (1956). The stress of life. McGraw-Hill. 
Shockley, K. M., Clark, M. A., Dodd, H., \& King, E. B. (2020). Work-family strategies during COVID19: Examining gender dynamics among dual-earner couples with young children. Journal of Applied Psychology, 106(1), 15-28. https://doi.org/10.1037/ap10000857

Sinclair, R. R., Allen, T., Barber, L., Bergman, M., Britt, T., Butler, A., Ford, M., Hammer, L., Probst, T., \& Yuan, Z. (2020). Occupational health science in the time of COVID-19: Now more than ever. Occupational Health Science, 4, 1-22. https://doi.org/10.1007/s41542-020-00064-3

Sonnentag, S. \& Frese, M. (2003). Stress in organizations. In W. C. Borman, D. R. Ilgen \& R. J. Klimiski (Eds.), Comprehensive handbook of psychology (vol.12, p.453-491). Wiley.

Statistics Canada. (2020a, mai). La santé mentale des Canadiens durant la pandémie de COVID-19. (publication no 11-001-X). https://www150.statcan.gc.ca/n1/dailyquotidien/200527/dq200527b-fra. htm

Statistics Canada. (2020b, mai). Les arrêts de travail et la vulnérabilité financière. (publication no 45280001). https://www150.statcan.gc.ca/n1/fr/pub/45-280001/2020001/article/00010-fra.pdf?st= XV5TzHOt

Statistics Canada. (2020c, avril). Série d'enquête sur les perspectives canadienne 1: La COVID-19 et travailler à la maison, 2020 (publication no 11-001-X). https://www150.statcan.gc.ca/n1/fr/daily-quoti dien/200417/dq200417a-fra.pdf?st=UMUDRcMg

St-Hilaire, F., Gilbert, M.-H., \& Lefebvre, R. (2018). Managerial practices to reduce psychological risk exposure: A competency-based approach. Canadian Journal of Administrative Sciences, 35(4), 535-550. https://doi.org/10.1002/cjas.1506

Suzuki Y., Fukasawa M., Obawa A. \& Kim Y. (2014). Mental health distress related factors among prefectural public servants seven month after the great East Japan Earthquake. Journal of Epidemiology, 24(4), 287-294. https://doi.org/10.2188/jea.JE20130138

Tabachnick, B. G., \& Fidell, L. S. (2013). Using multivariate statistics, 6th Edn. Northridge. CA: California State University.

Tam, C. W. C., Pang, E. P. F., Lam, L. C. W., \& Chiu, H. F. K. (2004). Severe acute respiratory syndrome (SARS) in Hong Kong in 2003: Stress and psychological impact among frontline healthcare workers. Psychological Medecine, 34(7), 1197-1204. https://doi.org/10.1017/S0033291704002247

Tavares, A. I. (2017). Telework and health effects review. International Journal of Healthcare, 3(2), 30-36. https://doi.org/10.5430/ijh.v3n2p30

Väänänen, A., Toppinen-Tanner, S., Kalimo, R., Mutanen, P., Vahtera, J., \& Peiro, J. M. (2003). Job characteristics, physical and psychological symptoms and social support as antecedents of sickness absence among men and women in the private sector. Social Science \& Medecine, 57(5), 807-824. https://doi.org/10.1016/S0277-9536(02)00450-1

Veit, C. T., \& Ware, J. E. (1983). The structure of psychological distress and well-being in general populations. Journal of Consulting and Clinical Psychology, 51(5), 730-742. https://doi.org/10.1037/ 0022-006X.51.5.730

Waghorn, G., \& Chant, D. (2006). Work performance among Australians, with depression and anxiety disorders: A population level second order analyses. The Journal of Nervous and Mental Disease, 184(12), 898-904. https://doi.org/10.1097/01.nmd.0000243012.91668.a5

Watson, K. D. (2007). Remote management: Traditional leadership behaviors in a contemporary work environment [doctoral dissertation, Kansas State University]. K-State Research Exchange.https:// krex.kstate.edu/dspace/bitstream/handle/2097/432/KelleyWatson2007.pdf? sequence=1\&isAll owed=y

Westman, M., Hobfoll, S., Chen, S., Davidson, O., \& Laski, S. (2005). Organizational stress through the lens of conservation of ressources (COR) theory. Exploring interpersonal dynamicsIn P. L. Perrewé \& D. C. Ganster (Eds.), Research in occupational stress and well-being (Vol. 4, pp. 167-220). Elsevier/JAI.

World Health Organization. (2020). Policy brief: COVID-19 and the need for action on mental health. World Health Organization. https://unsdg.un.org/sites/default/files/2020-05/UN-Policy -BriefCOVID-19-and-mental-health.pdf

Wright, T. A., \& Cropanzano, R. (1998). Emotional exhaustion as a predictor of job performance and voluntary turnover. Journal of Applied Psychology, 83(3), 486-493. https://doi.org/10.1037/00219010.83.3.486

Wright, T. A., \& Cropanzano, R. (2000). Psychological well-being and job satisfaction as predictors of job performance. Journal of Occupational Health Psychology, 5(1), 84-94. https://doi.org/10.1037/ 1076-8998.5.1.84 


\section{Authors and Affiliations}

Sophie Meunier ${ }^{1}$. Laurence Bouchard' ${ }^{1}$. Simon Coulombe ${ }^{2}$. Marina Doucerain ${ }^{1} \cdot$ Tyler Pacheco $^{3}$. Emilie Auger ${ }^{2}$

$\triangle$ Laurence Bouchard

bouchard.laurence.2@courrier.uqam.ca

1 Department of Psychology, Université du Québec à Montréal, H3C 3P8 Montréal, Canada

2 Université Laval, Québec, Canada

3 Wilfrid Laurier University, Waterloo, Canada 